\title{
Serum Iron Status of Children with Cyanotic Congenital Heart Disease in Lagos, Nigeria
}

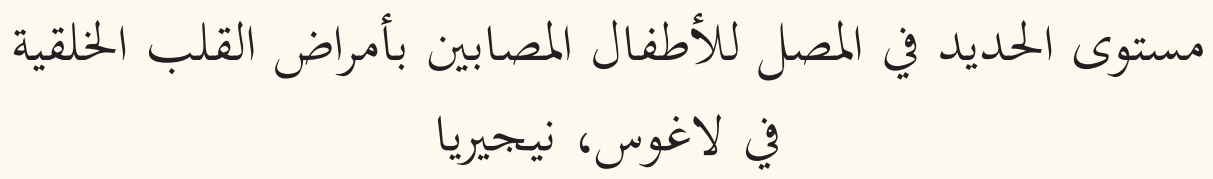

اديجوموكي إتيولا، بركات انيماساهون، اوليساميدوا نجوكانما

ABSTRACT: Objectives: Cyanotic congenital heart disease (CCHD) predisposes patients to iron deficiency due to compensatory secondary erythrocytosis. This study aimed to determine the serum iron status and prevalence of iron deficiency among children with cyanotic congenital heart disease attending the Paediatric Cardiology outpatient clinic of Lagos State University Teaching Hospital, Lagos, Nigeria. Methods: This cross-sectional casecontrol study took place between May and October 2015 at the Lagos State University Teaching Hospital. A total of 75 children with cyanotic congenital heart disease and 75 apparently healthy age-, gender- and socioeconomicallymatched controls were analysed to determine serum iron status and the prevalence of iron deficiency as defined by the World Health Organization criteria. Results: The mean age of the children was $47.5 \pm 2.9$ months (range: 6-144 months old). Iron deficiency was significantly more frequent among CCHD patients compared to control subjects $(9.3 \%$ versus $0 \% ; P=0.006)$. While latent iron deficiency was more prevalent among children in the control group compared to those with CCHD, this difference was not statistically significant (13.3\% versus 9.3\%; $P=0.303$ ). No cases of iron deficiency anaemia were observed in the studied sample. Conclusion: Neither the children in the control group nor those with CCHD had iron deficiency anaemia. However, iron deficiency was significantly more prevalent among children with CCHD in Lagos. Periodic serum iron status screening is therefore recommended for this population.

Keywords: Congenital Heart Defects; Cyanosis; Iron Deficiency Anemia; Children; Case-Control Studies; Nigeria.

الملخص: الههف: يؤهب مرض القلب الخلقي المزمن المرضى لنقص الحديد بسبب كثرة كريات الدم الحمراء التعويضية. هدفت هذه الدراسة

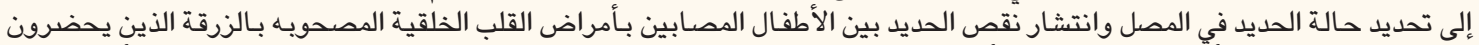

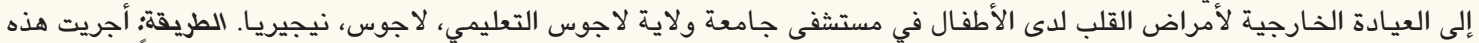

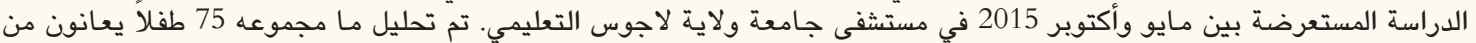

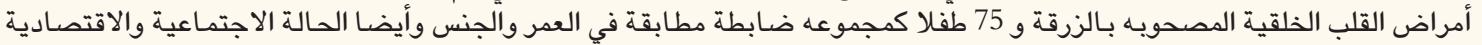

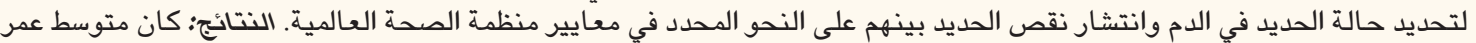

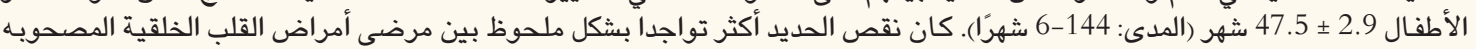

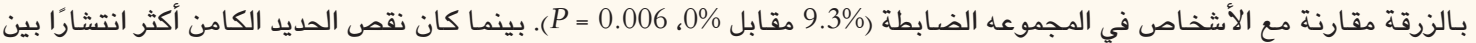

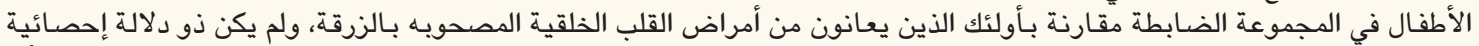

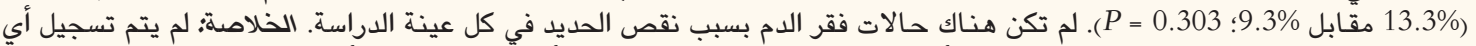

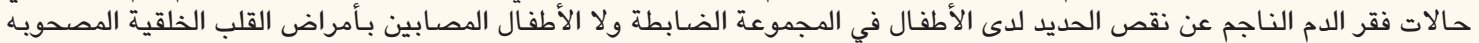

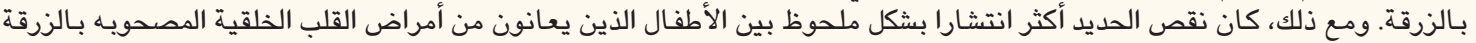
في لاجوس. لذلك ينصح فحص ذلك حالة الحديد في المصل الدوري لهذي لهذه الفئة من السكان.

الكلمات المفتاحية؛ عيوب القلب الخلقية؛ زرقة؛ فقر الدم بعوز الحديد؛ الأطفال؛ دراسات الحالات والهجموعة الضابطة؛ نيجيريا.

\section{AdVANCES IN KNOWLEDGE}

This study found iron deficiency to be significantly more prevalent among children with cyanotic congenital heart disease (CCHD) compared to a matched control group.

No cases of iron deficiency were noted among children in the control group according to the criteria of the World Health Organization; however, latent iron deficiency was more common in the control group.

\section{Application to Patient Care}

Based on these findings, periodic serum iron status assessment and treatment is recommended for children with CCHD in this setting. As children of both groups were found to have latent iron deficiency, routine counselling would also be beneficial for the caregivers of children to stress the importance of iron-rich foods and meal fortification. 
$\mathrm{C}$ YANOTIC CONGENITAL HEART DISEASE (CCHD) is characterised by hypoxia resulting in physiologically-increased erythropoiesis which, if unabated, leads to iron deficiency. ${ }^{1}$ This predisposes children to growth retardation, impaired immune function, delayed behavioural, mental and psychomotor development and decreased work capacity. ${ }^{2-5}$ The extreme manifestation of iron deficiency is an anaemic state. ${ }^{6}$ However, the clinical detection of anaemia based on pallor is hampered by the occurrence of hypoxia-induced polycythaemia in CCHD. ${ }^{7}$ Laboratory tests and periodic screening are therefore mandatory for diagnosis. ${ }^{8}$

Overall, CCHD accounts for an estimated third of congenital heart disease cases. ${ }^{9}$ Treatment is usually surgical, with the cost of repair ranging from $\$ 10,000-$ $\$ 50,000$ USD, depending on setting. ${ }^{10}$ Unfortunately, this is often beyond the economic means of the average Nigerian family; as such, surgical correction of the defect is usually delayed due to financial constraints. ${ }^{10,11}$ Accordingly, CCHD-related comorbidities such as iron deficiency should be treated promptly to improve clinical outcomes in affected children. However, there is a paucity of local studies on the iron status of Nigerian children with CCHD, particularly in settings where iron deficiency and iron deficiency anaemia are reportedly common. ${ }^{11-13}$ A recent study reported that the prevalence of iron deficiency among children with CCHD in Ibadan, Nigeria, was high (35\%). ${ }^{11}$

Conventional tests for iron deficiency such as mean corpuscular volume, serum ferritin levels and transferrin saturation (TSAT) have limited value due to varying sensitivities and specificities, especially as results may be affected by acute or chronic inflammatory conditions, genetic polymorphisms and sickle cell disease states. ${ }^{12,14,15}$ Other researchers have also reported that expected microcytic, hypochromic and erythrocyte findings are often absent in cyanotic patients with iron deficiency. ${ }^{16}$ This study aimed to assess serum iron status and the prevalence of iron deficiency among children with CCHD in Lagos, Nigeria, in comparison to a matched control group. The research questions for the study were: (1) what is the prevalence of iron deficiency in children with cyanotic congenital heart disease; and (2) what is the prevalence of iron deficiency anaemia in children with cyanotic congenital heart disease. The null hypotheses were: (1) there is no statistically significant difference between the prevalence of iron deficiency in children with cyanotic congenital heart disease and those of the appropriate age- and gender-matched controls; and (2) there is no statistically significant difference between the prevalence of iron deficiency anaemia in children with cyanotic congenital heart disease and those of the appropriate age- and gender-matched controls. These findings are expected to increase awareness regarding the need for routine monitoring and prompt treatment, thereby reducing morbidity in this patient group.

\section{Methods}

This cross-sectional case-control study was carried out between May and October 2015 at the Department of Paediatrics at Lagos State University Teaching Hospital which is an urban tertiary healthcare centre in Ikeja, Lagos, Nigeria. A total of 150 children were recruited consecutively over the six-month period, including 75 consecutive children with CCHD and 75 control subjects matched for age, gender and socioeconomic status. Classification and matching for the latter variable was performed according to previous research. ${ }^{17}$

The estimated sample size was determined according to the following equation for comparative studies: ${ }^{18}$

$$
\mathrm{N}=\frac{\left(Z_{\alpha}+Z_{\beta}\right)^{2} \times 2 p(1-p)}{d^{2}} \quad[\text { Equation } 1]
$$

where $Z_{\alpha}$ is the normal standard deviation corresponding to a $95 \%$ confidence interval (1.96), $Z_{\beta}$ is the power set at $80 \%(0.84), p$ is the average of previously reported prevalence rates of iron deficiency in children with CCHD (16.9\%) and controls (27.5\%) and $d$ is the minimum difference to be detected by the study (20\%). ${ }^{19}$ This calculation resulted in a minimum of 67 subjects; however, as the non-response rate was set at $10 \%$, the final number of subjects was calculated to be 74. This was then rounded up to 75 subjects for ease of calculation, each of whom were subsequently matched for age, gender and socioeconomic class with a control subject.

In terms of inclusion criteria, the case group included patients diagnosed with echocardiographyconfirmed CCHD attending the outpatient paediatric cardiology clinic who had not undergone corrective surgery and who were between six months and 12 years old. Only subjects who had had no symptoms or signs attributable to an acute illness within the preceding four weeks were included in the study. Children who had undergone a partial exchange transfusion, blood transfusion or repeated phlebotomy in the past three months were excluded, as well as those who had received iron supplementation prior to recruitment or had been diagnosed with sickle cell anaemia or other chronic illnesses. The control group comprised of apparently healthy children recruited from general 
outpatient clinics and other specialty clinics within the same age range. Children were deemed healthy if they had had no symptoms or signs attributable to illness within the preceding four weeks.

Children in both the case and control groups underwent venepuncture performed according to the guidelines of the World Health Organization (WHO). ${ }^{20}$ An LH 750 Hematology Analyser (Beckman Coulter Inc., Brea, California, USA) was used to perform an automated complete blood count using whole blood samples with ethylenediaminetetraacetic acid added. Serum ferritin levels were measured using a human ferritin enzyme immunoassay test kit with a calibration range of $0-800 \mathrm{ng} / \mathrm{mL}$ (Ferritin AccuBind ELISA Kit, Monobind Inc., Lake Forest, California, USA). Serum iron levels and total iron-binding capacity (TIBC) were measured using a reagent set (TECO Diagnostics, Anaheim, California, USA). Unsaturated iron-binding capacity was determined by adding ferrous iron ions to the serum so that they would bind to transferrin at unsaturated binding sites..$^{21}$

As per the WHO criteria, a diagnosis of iron deficiency was defined according to cut-off serum ferritin levels of $<12 \mathrm{ng} / \mathrm{L}$ or $<15 \mathrm{ng} / \mathrm{L}$ for children aged $<5$ years old and $\geq 5$ years old, respectively. ${ }^{8}$ In turn, iron deficiency anaemia was diagnosed for subjects with serum ferritin levels of $<12 \mathrm{ng} / \mathrm{L}$ or $<15 \mathrm{ng} / \mathrm{L}$ for children aged $<5$ years old and $\geq 5$ years old, respectively, in the presence of haemoglobin concentrations at least two standard deviations below that of the normal population at the same age. ${ }^{22}$

All data collected were stored on a personal computer. Statistical analysis was performed using an Excel spreadsheet, Version 2010 (Microsoft Inc., Redmond, Washington, USA) and the Statistical Package for the Social Sciences (SPSS), Version 20.0 (IBM Corp., Armonk, New York, USA). Means, medians, standard deviations and ranges were calculated for continuous variables, while categorical variables were represented as frequencies and percentages. Continuous variables were compared using a Student's t-test, while categorical variables were compared with Fisher's exact test. A Kolmogorov-Smirnov nonparametric test was used to determine the normality of continuous data; subsequently, a Student's t-test was used to compare normally-distributed data, while a Mann-Whitney U test was used for skewed or non-normally distributed data. The degree of agreement between different methods used to evaluate the same parameter was estimated using Kappa statistics. A P value of 0.050 was deemed statistically significant.

Ethical approval for this study was obtained from the Ethics Committee of Lagos State University Teaching
Hospital (LREC/10/06/398). Written informed consent was obtained from the parents/caregivers of participants. Moreover, all children found to be iron-deficient during the course of the study received prompt and appropriate treatment.

\section{Results}

This study included 150 children, of which 75 were CCHD patients and 75 were apparently healthy controls [Equation 1]. The mean age of the children was $47.5 \pm 2.9$ months (range: 6-144 months old). In terms of age distribution, 26 children with CCHD (34.7\%) were <24 months old, 30 (40\%) were between 24-59 months old and 19 (25.3\%) were $\geq 60$ months old. As the controls were age-matched, there were equal numbers of children in each age group in the control group. In the CCHD group, Tetralogy of Fallot (TOF) was the most common heart lesion (52\%), followed by double-outlet right ventricle (DORV; 12\%). The least common diagnoses were Ebstein anomalies and complex heart disease (1.3\% each) [Table 1]. Although all of the study population had normal haemoglobin concentrations, mean haemoglobin concentrations were significantly higher among children with CCHD compared to those in the control group $(13.8 \pm 3.9 \mathrm{~g} / \mathrm{dL}$ versus $10.3 \pm 0.8 \mathrm{~g} / \mathrm{dL} ; P<0.001)$.

Mean serum iron, serum ferritin, TIBC and TSAT values were compared between children with CCHD and apparently healthy controls according to age group. Among children aged 6-23 months, mean serum iron levels were significantly lower in the CCHD group compared to the control group $(162.8 \pm 10.8 \mu \mathrm{g} / \mathrm{dL}$

Table 1: Frequency of heart lesions among children with cyanotic congenital heart disease in Lagos, Nigeria $(N=75)$

$\begin{array}{lc}\text { Lesion } & \text { n (\%) } \\ \text { Tetralogy of Fallot } & 39(52) \\ \text { Double-outlet right ventricle } & 9(12) \\ \text { TGA } & 6(8) \\ \text { Critical pulmonary stenosis } & 4(5.3) \\ \text { Eisenmenger complex } & 4(5.3) \\ \text { Pulmonary atresia with VSD } & 4(5.3) \\ \text { Truncus arteriosus } & 3(4) \\ \text { Tricuspid atresia } & 2(2.7) \\ \text { TAPVC } & 2(2.7) \\ \text { Ebstein anomaly } & 1(1.3) \\ \text { Complex heart disease } & 1(1.3)\end{array}$

$T G A=$ transposition of the great arteries; VSD = ventricular septal defect; TAPVC = total anomalous pulmonary venous connection. 
Table 2: Iron status parameters among 6-23-month-old children with cyanotic congenital heart disease and age-matched controls in Lagos, Nigeria $(\mathrm{N}=52)$

\begin{tabular}{|c|c|c|c|c|}
\hline Parameter & \multicolumn{2}{|c|}{ Mean \pm SD; median (range) } & Z score & $P$ value ${ }^{*}$ \\
\hline Serum iron in $\mu \mathrm{g} / \mathrm{dL}$ & $162.8 \pm 10.8 ; 166.4(130.3-175.9)$ & $171.6 \pm 5.6 ; 173.9(154.8-176.4)$ & 3.555 & $<0.001^{\dagger}$ \\
\hline Serum ferritin in $\mathrm{ng} / \mathrm{dL}$ & $80.4 \pm 56.3 ; 62.0(2.0-200.0)$ & $52.5 \pm 27.2 ; 43.0(18.0-110.0)$ & 1.678 & 0.093 \\
\hline $\mathrm{TIBC}$ in $\mu \mathrm{g} / \mathrm{dL}$ & $379.8 \pm 111.5 ; 414.2(111.7-579.3)$ & $351.7 \pm 98.4 ; 344.8(182.8-577.8)$ & 1.206 & 0.228 \\
\hline
\end{tabular}

$S D=$ standard deviation; $C C H D=$ cyanotic congenital heart disease; TIBC = total iron-binding capacity; TSAT = transferrin saturation .

*Using a Mann-Whitney U test. ${ }^{\dagger}$ Statistically significant at $P<0.050$.

Table 3: Iron status parameters among 24-59-month-old children with cyanotic congenital heart disease and age-matched controls in Lagos, Nigeria $(\mathrm{N}=60)$

\begin{tabular}{lcccc} 
Parameter & \multicolumn{2}{c}{ Mean \pm SD; median (range) } & Z score & $P_{\text {value }}^{*}$ \\
& CCHD group $(\mathbf{n}=30)$ & Control group $(\mathbf{n}=30)$ & 3.818 \\
Serum iron in $\mu \mathrm{g} / \mathrm{dL}$ & $167.7 \pm 39.7 ; 161.4(141.4-357.6)$ & $169.7 \pm 7.3 ; 170.7(148.0-179.4)$ & $<0.001^{\dagger}$ \\
Serum ferritin in $\mathrm{ng} / \mathrm{dL}$ & $61.9 \pm 52.1 ; 39.0(2.0-205.0)$ & $87.7 \pm 63.2 ; 4.0(12.0-220.0)$ & 1.504 & 0.133 \\
TIBC in $\mu \mathrm{g} / \mathrm{dL}$ & $392.1 \pm 98.1 ; 396.1(209.9-500.5)$ & $352.5 \pm 81.5 ; 338.8(224.3-582.1)$ & 1.637 & 0.102 \\
TSAT in $\%$ & $45.3 \pm 14.0 ; 40.9(26.1-80.0)$ & $60.4 \pm 10.9 ; 50.7(30.3-76.1)$ & 1.904 & 0.057
\end{tabular}

$S D=$ standard deviation; $C C H D=$ cyanotic congenital heart disease; $T I B C=$ total iron-binding capacity; TSAT = transferrin saturation *Using a Mann-Whitney $U$ test. ${ }^{\dagger}$ Statistically significant at $P<0.050$.

Table 4: Iron status parameters among 60-144-month-old children with cyanotic congenital heart disease and age-matched controls in Lagos, Nigeria $(\mathrm{N}=38)$

\begin{tabular}{lcccc} 
Parameter & \multicolumn{2}{c}{ Mean \pm SD; median (range) } & Z score $^{P}$ value* \\
& CCHD group $(\mathbf{n}=19)$ & Control group $(\mathbf{n}=19)$ & 3.338 \\
Serum iron in $\mu \mathrm{g} / \mathrm{dL}$ & $163.1 \pm 5.6 ; 162.1(152.0-178.9)$ & $169.6 \pm 10.3 ; 173.3(138.5-179.1)$ & $0.001^{\dagger}$ \\
Serum ferritin in $\mathrm{ng} / \mathrm{dL}$ & $82.5 \pm 61.5 ; 8.0(7.0-201.0)$ & $62.2 \pm 58.3 ; 40.0(13.0-215.0)$ & 1.306 \\
TIBC in $\mu \mathrm{g} / \mathrm{dL}$ & $394.5 \pm 112.7 ; 407.7(218.1-632.8)$ & $370.7 \pm 96.6 ; 381.4(133.9-524.9)$ & 0.554 & 0.174 \\
TSAT in \% & $44.9 \pm 14.6 ; 39.6(26.9-82.0)$ & $50.4 \pm 20.9 ; 46.2(30.9-129.2)$ & 0.932 & 0.351
\end{tabular}

$S D=$ standard deviation; $C C H D=$ cyanotic congenital heart disease; $T I B C=$ total iron-binding capacity; TSAT = transferrin saturation .

*Using a Mann-Whitney U test. ' Statistically significant at $P<0.050$.

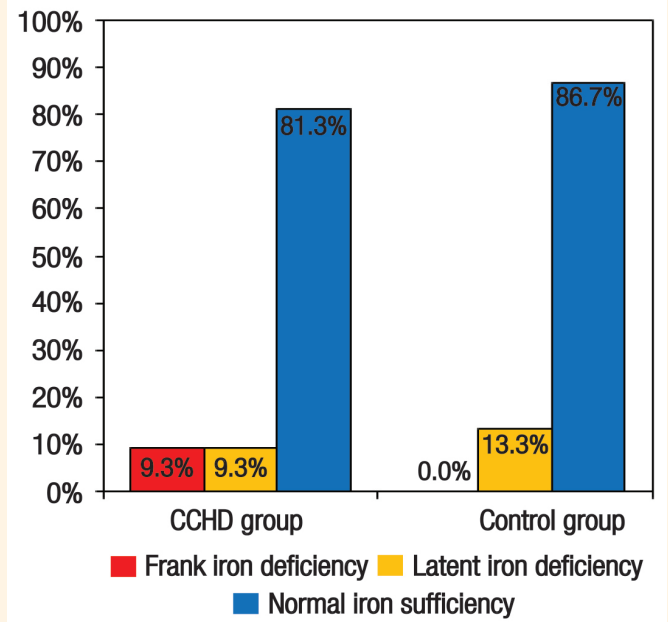

Figure 1: Prevalence of iron deficiency among children with cyanotic congenital heart disease and age-matched controls in Lagos, Nigeria ( $\mathrm{N}=150)$.

$C C H D=$ cyanotic congenital heart disease. versus $171.6 \pm 5.6 \mu \mathrm{g} / \mathrm{dL} ; P<0.001)$; a similar finding was documented for TSAT $(48.7 \pm 24.9 \%$ versus $52.6 \pm$ $15.0 \% ; P=0.040)$. However, there were no significant intergroup differences regarding mean TIBC and serum ferritin levels [Table 2].

For the 24-59-month-old age group, serum iron levels were also significantly lower in the CCHD group compared to controls $(167.7 \pm 39.7 \mu \mathrm{g} / \mathrm{dL}$ versus $169.7 \pm 7.3 \mu \mathrm{g} / \mathrm{dL} ; P<0.001)$, although none of the other biochemical parameters were significantly different between the CCHD and control groups [Table 3]. Similar findings were noted for 60-144-month-old children, with serum iron levels significantly reduced in the CCHD group $(163.1 \pm 5.6 \mu \mathrm{g} / \mathrm{dL}$ versus $169.6 \pm 10.3 \mu \mathrm{g} / \mathrm{dL}$; $P=0.001$ ), while none of the other biochemical parameters differed significantly [Table 4].

The prevalence rates of frank and latent iron deficiency are shown in Figure 1. Overall, seven (9.3\%) children with CCHD had an iron deficiency whereas 
Table 5: Iron status parameters according to iron sufficiency among children with cyanotic congenital heart disease in Lagos, Nigeria $(\mathrm{N}=75)$

\begin{tabular}{|c|c|c|c|c|}
\hline \multirow[t]{2}{*}{ Parameter } & \multicolumn{2}{|c|}{ Mean \pm SD } & \multirow[t]{2}{*}{ t value } & \multirow[t]{2}{*}{$P$ value } \\
\hline & Iron-deficient children $(\mathbf{n}=7)$ & Iron-sufficient children $(n=68)$ & & \\
\hline Serum ferritin in ng/dL & $7.7 \pm 4.6$ & $84.0 \pm 11.7$ & 3.664 & $<0.001^{*}$ \\
\hline TSAT in $\%$ & $43.0 \pm 17.7$ & $46.5 \pm 14.1$ & 0.598 & 0.522 \\
\hline
\end{tabular}

$S D=$ standard deviation; TIBC = total iron-binding capacity; TSAT = transferrin saturation. "Statistically significant at P $<0.050$.

iron deficiency was not documented among the control group (9.3\% versus $0 \% ; P=0.006)$. In contrast, latent iron deficiency was found to be more common in controls compared to subjects with CCHD; however, this difference was not significant (13.3\% versus 9.3\%; $P=0.303)$. No cases of iron deficiency anaemia were documented in the study population in either group. In terms of specific heart diseases, three (7.7\%) out of 39 children with TOF, two (33.3\%) out of six with TGA and one (11.1\%) out of nine with DORV were irondeficient. The remaining iron-deficient child was the only patient with an Ebstein anomaly. With regards to age, iron deficiency occurred in five (8.9\%) out of 56 and two (10.5\%) out of 19 children who were $<5$ and $\geq$ 5 years old, respectively.

In the CCHD group, mean serum ferritin levels were significantly lower in iron-deficient subjects compared to those who were iron-sufficient $(7.7 \pm 4.6$ $\mathrm{ng} / \mathrm{dL}$ versus $84.0 \pm 11.7 \mathrm{ng} / \mathrm{dL} ; P<0.001)$, while the mean TIBC was significantly higher in iron-deficient subjects $(479.5 \pm 98.7 \mu \mathrm{g} / \mathrm{dL}$ versus $377.2 \pm 104.7$ $\mu \mathrm{g} / \mathrm{dL} ; P=0.017)$. However, there was no significant difference in mean serum iron levels and TSAT between iron-deficient and iron-sufficient children with CCHD [Table 5].

\section{Discussion}

The overall prevalence of iron deficiency among children with CCHD in the current study was $9.3 \%$. Other researchers have reported comparable prevalence rates of $12.5 \%$ and $16.9 \%$ in Italy and Kenya, respectively. ${ }^{19,23}$ Similarities in these rates may be related to the age groups of the targeted populations, as both of the aforementioned studies recruited children up to 12 years of age..$^{19,23}$ However, much higher rates have been reported in Turkey (52.5-63.6\%). ${ }^{24,25}$ This may again be due to population variation, as iron deficiency is reportedly higher in children under five years. ${ }^{13}$ Nevertheless, when the analysis in the present study was limited to under-five-year-olds, the prevalence rate was $8.9 \%$, which is still much lower than that reported in Turkey. ${ }^{24,25}$
Aside from methodological differences, other explanations for differing prevalence rates may be due to local geographical and nutritional factors beyond the scope of the present study. It is unlikely that the difference is due to the specific CCHD type, as both the current study and previous studies reported similar frequencies of various heart lesions. ${ }^{22-25}$ In the present study, the spectrum of CCHD followed expected patterns, with TOF accounting for more than half of all patients. Other heart diseases identified were consistent with those reported in previous research from Nigeria. ${ }^{26}$

Although the prevalence of iron deficiency among children with CCHD was low in the present study, it was still significantly higher than that noted among the age-, gender- and socioeconomicallymatched controls, in whom no documented case of iron deficiency was observed. This finding supports the theory that chronic hypoxia results in increased haemopoiesis and iron depletion in children with CCHD. ${ }^{7}$ Nevertheless, it is worth noting that even though none of the control group met the WHO criteria for diagnosing frank iron deficiency, latent iron deficiency was more frequently diagnosed in this group compared to the CCHD group (13.3\% versus $9.3 \%)$.

Frank and latent iron deficiency refer to the progressive depletion of iron stores on a continuum. The deterioration of iron status from iron sufficiency to latent deficiency has been demonstrated in a longitudinal study of patients with $\mathrm{CCHD}^{24}$ It is therefore pertinent to address the importance of iron fortification in the general population and iron supplementation in iron-deficient children with CCHD. Such measures will help to reduce the morbidities to which children with iron deficiency are predisposed, including growth retardation, impaired immune function, impaired behavioural, mental and psychomotor development and decreased work capacity. ${ }^{2-5}$

In the present study, children with CCHD had significantly higher mean haemoglobin concentrations in comparison to healthy controls. This finding is in line with previous research. ${ }^{11}$ An uncorrected 
congenital cyanotic heart lesion keeps the body in a state of constant hypoxia. ${ }^{27}$ Hypoxia, in turn, triggers the physiological release of erythropoietin which stimulates the bone marrow to produce more erythrocytes, leading to an increase in oxygen-carrying capacity. ${ }^{28}$ Moreover, mean serum iron levels in the current study were significantly lower in the CCHD group compared to the controls, regardless of age. Previously documented studies have reported similar findings. ${ }^{5,24}$

In CCHD, low serum iron levels can be explained by the presence of hypoxaemia in which adaptive mechanisms increase the delivery of oxygen to the tissue, resulting in a rightward shift in the oxygenhaemoglobin dissociation curve. Persistent hypoxia and the corresponding increase in red cell mass place a continuous demand on iron stores, predisposing children with CCHD to iron deficiency. ${ }^{27}$ Mean TIBC values were also higher in the present study among iron-deficient compared to iron-sufficient children with CCHD; Soliman et al. reported similar findings. ${ }^{2}$ As a parameter, TIBC indicates the maximum amount of iron needed to saturate transferrin, the primary protein involved in iron transport. ${ }^{6}$ Thus it is not surprising that mean TIBC is higher in the presence of iron deficiency.

The findings of the current study answered the previously posed research questions. There was a significant difference in the number of $\mathrm{CCHD}$ cases with iron deficiency compared to the controls, allowing for the rejection of the null hypothesis proposed for the first research question. Moreover, a pattern suggestive of progressive iron depletion was observed, with patients manifesting both latent and frank iron deficiency. However, none of the subjects had iron deficiency anaemia; hence, the null hypothesis can be accepted for the second research question.

This study was subject to certain limitations. C-reactive protein, a marker of inflammation was not measured; this could have been a confounding cause of elevated serum ferritin. However, efforts were made to exclude subjects with symptoms and or signs of infections within four weeks preceding the study. In addition, it would have been ideal to perform bone marrow aspiration, which is the gold standard test for iron deficiency, however the invasive nature of this procedure was not feasible, acceptable or costeffective in the present study.

The current study was able to demonstrate the occurrence of iron deficiency in subjects with CCHD and document the presence of latent iron deficiency in children with CCHD and apparently healthy controls. This emphasises the need for periodic iron status checks of these children and nutritional counselling for parents of children attending the Lagos State University Teaching Hospital.

\section{Conclusion}

In Lagos, Nigeria, the prevalence of iron deficiency among children with CCHD was 9.3\%. Routine serum iron status assessment should therefore be carried out periodically in this setting, with those children found deficient referred for treatment. Latent iron deficiency was also fairly common among both CCHD subjects and apparently healthy controls. Accordingly, parents and caregivers should be routinely counselled on the importance of iron-rich foods and the benefits of meal fortification, regardless of disease status.

\section{CONFLICT OF INTEREST}

The authors declare no conflicts of interest.

\section{FUNDING}

No funding was received for this study.

\section{References}

1. Tempe DK, Virmani S. Coagulation abnormalities in patients with cyanotic congenital heart disease. J Cardiothorac Vasc Anesth 2002;16:752-65.https://doi.org/10.1053/jcan.2002.128436.

2. Soliman AT, Al Dabbagh MM, Habboub AH, Adel A, Humaidy NA, Abushahin A. Linear growth in children with iron deficiency anemia before and after treatment. J Trop Pediatr 2009; 55:324-7. https://doi.org/10.1093/tropej/fmp011.

3. Beard J, deRegnier RA, Shaw MD, Rao R, Georgieff M. Diagnosis of iron deficiency in infants. Lab Med 2007; 38:103-8. https://doi.org/10.1309/7KJ11RX758UKLXXM.

4. Lozoff B, Jimenez E, Wolf AW. Long-term developmental outcome of infants with iron deficiency. N Engl J Med 1991; 325:687-94. https://doi.org/10.1056/NEJM199109053251004.

5. Tay EL, Peset A, Papaphylactou M, Inuzuka R, AlonsoGonzalez R, Giannakoulas G, et al. Replacement therapy for iron deficiency improves exercise capacity and quality of life in patients with cyanotic congenital heart disease and/or the Eisenmenger syndrome. Int J Cardiol 2011; 151:307-12. https://doi.org/10.1016/j.ijcard.2010.05.066.

6. Thompson RB, Proctor SJ, Eds. A Short Textbook of Haematology, 6th ed. London, UK: Urban \& Schwarzenberg, 1984. Pp. 153-87.

7. Rosove $\mathrm{MH}$, Perloff JK, Hocking WG, Child JS, Canobbio MM, Skorton DJ. Chronic hypoxaemia and decompensated erythrocytosis in cyanotic congenital heart disease. Lancet 1986; 2:313-15. https://doi.org/10.1016/s0140-6736(86)90005-x.

8. World Health Organization. Iron deficiency anemia: Assessment, prevention and control - A guide for programme managers. From: www.who.int/nutrition/publications/micron utrients/anaemia_iron_deficiency/WHO_NHD_01.3/en/ Accessed: Jun 2019.

9. Olney RS, Ailes EC, Sontag MK. Detection of critical congenital heart defects: Review of contributions from prenatal and newborn screening. Semin Perinatol 2015; 39:230-7. https://doi.org/10.1053/j.semperi.2015.03.007. 
10. Falase B, Sanusi M, Majekodunmi A, Ajose I, Idowu A, Oke D. The cost of open heart surgery in Nigeria. Pan Afr Med J 2013; 14:61. https://doi.org/10.11604/pamj.2013.14.61.2162.

11. Ogunkunle OO. Erythrocyte indices of iron status in children with cyanotic congenital heart disease at the University College Hospital, Ibadan. Niger J Paediatr 2013; 40:75-8. https://doi. org/10.4314/njp.v40i1.14.

12. Fajolu IB, Grange OA, Renner JK, Odunukwe NW, Njokanma OF, Ahmed OA, et al. Prevalence of iron deficiency in children 6-24 months in Lagos. Nig Q J Hosp Med 2007; 17:97-100. https://doi.org/10.4314/nqjhm.v17i3.12553.

13. Akodu OS, Disu EA, Njokanma OF, Kehinde OA. Iron deficiency anemia among apparently healthy pre-school children in Lagos, Nigeria. Afr Health Sci 2016; 16:61-8. https://doi.org/10.4314/ahs.v16i1.8.

14. Mangosongo B, Kalokola FM, Munubhi EK, Mpembeni R. Iron deficiency in sickle cell anaemia patients in Dar es Salaam, Tanzania. Tanzan Med J 2004; 19:6-8. https://doi.org/10.4314/ tmj.v19i1.39190.

15. Beard JL. Iron biology in immune function, muscle metabolism and neuronal functioning. J Nutr 2001; 131:568S-79S. https://doi.org/10.1093/jn/131.2.568S

16. Kaemmerer H, Fratz S, Braun SL, Koelling K, Eicken A, Brodherr-Heberlein S, et al. Erythrocyte indexes, iron metabolism, and hyperhomocysteinemia in adults with cyanotic congenital cardiac disease. Am J Cardiol 2004; 94:825-8. https://doi.org/10.1016/j.amjcard.2004.06.014.

17. Oyedeji GA. Socio-economic and cultural background of hospitalised children in Ilesha. Niger J Paediatr 1985; 12:111-17.

18. Kirkwood BR, Sterne JAC. Calculation of required sample size. In: Essential Medical Statistics, 2nd ed. Oxford, UK: WileyBlackwell, 2001. Pp. 413-28.

19. Lang'o MO, Githanga JN, Yuko-Jowi CA. Prevalence of iron deficiency in children with cyanotic heart disease seen at Kenyatta National Hospital and Mater Hospital Nairobi. East Afr Med J 2009; 86:S47-51. https://doi.org/10.4314/eamj. v86i12.62901.
20. World Health Organization. WHO guidelines on drawing blood: Best practices in phlebotomy. From: www.who.int/ infection-prevention/publications/drawing_blood_best/en/ Accessed: Jun 2019.

21. Obeagu EI, Eze VU, Alaeboh EA, Ochei KC. Determination of haematocrit level and iron profile study among persons living with HIV in Umuahia, Abia State, Nigeria. J BioInnovation 2016; 5:464-71.

22. Pesce MA. Reference ranges for laboratory tests and procedures. In: Kliegman RM, Behrman RE, Jenson HB, Stanton BF, Eds. Nelson Textbook of Pediatrics, 18th ed. Philadelphia, Pennsylvania, USA: Saunders, 2007. Pp. 2943-54.

23. Drossos C, Thanapoulos B, Papadimitrou T, Milingos M, Papadimitrou A, Kostantelloy E, et al. [Incidence of anemia in congenital heart diseases]. Pediatr Med Chir 1981; 3:309-12.

24. Onur CB, Sipahi T, Tavil B, Karademir S, Yoney A. Diagnosing iron deficiency in cyanotic heart disease. Indian J Pediatr 2003; 70:29-31. https://doi.org/10.1007/bf02722740.

25. Olcay L, Ozer S, Gürgey A, Saraçlar M, Ozme S, Bilgiç A, et al. Parameters of iron deficiency in children with cyanotic congenital heart disease. Pediatr Cardiol 1996; 17:150-4. https://doi.org/10.1007/BF02505204.

26. Animasahun BA, Madise-Wobo AD, Falase BA, Omokhodion SI. The burden of Fallot's tetralogy among Nigerian children. Cardiovasc Diagn Ther 2016; 6:453-8. https://doi.org/10.21037/ cdt.2016.05.04.

27. Perloff JK, Rosove MH, Child JS, Wright GB. Adults with cyanotic congenital heart disease: Hematologic management. Ann Intern Med 1988; 109:406-13. https://doi.org/10.7326/000 3-4819-109-5-406.

28. Jelkmann W. Regulation of erythropoietin production. J Physiol 2011; 589:1251-8. https://doi.org/10.1113/jphysiol.2010.195057. 